\title{
Review of Aerodynamic Design Configurations for Wind Mitigation in High-Rise Buildings: Two Cases from Amman
}

\author{
Sonia F. Al-Najjar ${ }^{1, *}$, Wael W. Al-Azhari ${ }^{2}$ \\ ${ }^{1}$ Department of Architecture, Khawarizmi University Technical College, Amman, P.O. Box 11953, Jordan \\ ${ }^{2}$ Department of Architecture Engineering, University of Jordan, Amman, P.O. Box 11942, Jordan
}

Received February 17, 2021; Revised March 19, 2021; Accepted April 22, 2021

\section{Cite This Paper in the following Citation Styles}

(a): [1] Sonia F. Al-Najjar, Wael W. Al-Azhari, "Review of Aerodynamic Design Configurations for Wind Mitigation in High-Rise Buildings: Two Cases from Amman," Civil Engineering and Architecture, Vol. 9, No. 3, pp. 708-720, 2021. DOI: 10.13189/cea.2021.090313.

(b): Sonia F. Al-Najjar, Wael W. Al-Azhari (2021). Review of Aerodynamic Design Configurations for Wind Mitigation in High-Rise Buildings: Two Cases from Amman. Civil Engineering and Architecture, 9(3), 708-720. DOI: 10.13189/cea.2021.090313.

Copyright $\bigcirc 2021$ by authors, all rights reserved. Authors agree that this article remains permanently open access under the terms of the Creative Commons Attribution License 4.0 International License

\begin{abstract}
This study is concerned with reviewing and analyzing methods used in early design stages to mitigate wind effects on high-rise buildings. In order to mitigate wind effects on structures and specifically high-rise buildings, early stage aerodynamic design decisions are made. Architects try to mitigate the wind effects on buildings by choosing the right form configuration like tapering or setbacks, etc., or by making vital decisions in the early design stage. However, structural engineers utilize the structural system that can best counter-act forces acting on the stability of the building. For both architects and engineers there are many tools which can be used in early design including advanced analysis methods, wind tunnel testing and wind studies combined with Computational Fluid Dynamics (CFD) simulations. This study reviews general architectural and structural design configurations performed in the early phases of the design process, for achieving structural stability, comfort and cost control. The research methodology depends on the study and analysis of different international building examples, and also by reviewing two local high-rise building cases in Amman, Jordan. The study concludes that there are many architectural aerodynamic configurations for the purpose of mitigating wind loads, which can be used as guidelines in the early design phases.
\end{abstract}

Keywords High-Rise Buildings, Wind Mitigation, Computational Fluid Dynamics (CFD), Model Configuration, Aerodynamic Design, Wind Tunnel Testing

\section{Introduction}

\subsection{Wind Effects on High-Rise Buildings}

The study of wind comfort and aerodynamic design for wind is new to Amman, Jordan, as there are a limited number of high-rise buildings in the city. This study aims to highlight the issue for interested researchers in the future. Amman is not considered a city that boasts of its high-rise buildings culture. On the contrary, the city has adopted regulations for high-rise buildings fairly recently. Unfortunately, when it comes to the design of high-rise buildings, special codes and regulations should be developed in order to control and ensure safety and stability. For structural engineers, on the one hand, the main aim is to stabilize the building against wind loads [1]. However, for architects, on the other hand, design optimization is of greatest importance. 


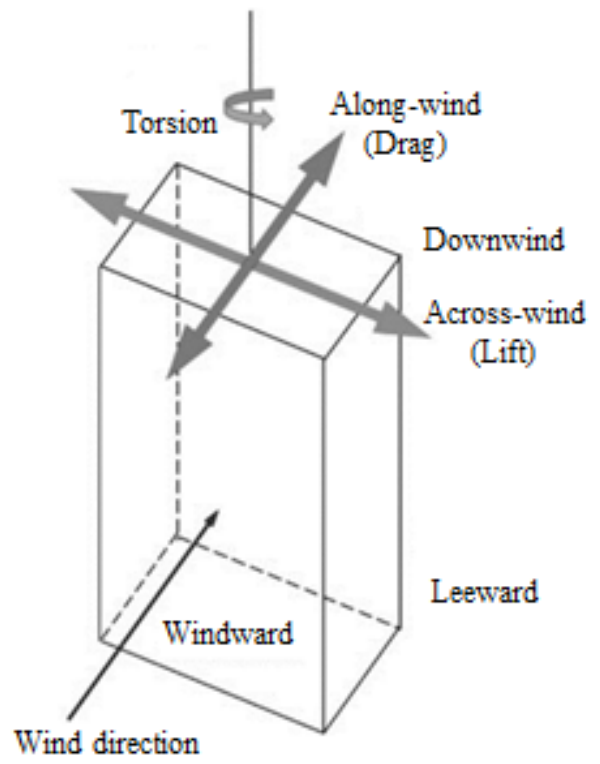

Figure 1. Dynamic Wind Loads Effects on High-Rise Buildings [5]

By adopting architectural aerodynamic measures in high-rise buildings, architects and engineers help combat forces acting in the along-wind and across-wind directions. For both architects and engineers, wind analysis can be a complicated issue, because of the effect of the distortion of the flow pattern around a high-rise building, which causes the formation of vortices, eddies, and the development of the wake in the surrounding environment [2]. As a result, high-rise buildings may oscillate, and wind loads can affect high-rise buildings in the along-wind direction, across-wind direction, or may cause torsional force [3], as illustrated in Figure 1. This will be largely affected by the building characteristics and configurations, and by the wind characteristics [4]. All of these are mitigated by adopting general guidelines for model and plan configuration, or by applying structural systems that help stabilize high-rise structures.

In the early design stages, shape and form of buildings can directly affect the buildings response to wind effects, and usually aerodynamic shapes, mainly those with rounded or softened corners can decrease the effects of wind loads, which can be seen in Figure 2.

The architectural design guidelines to mitigate wind effects on structures and specifically high-rise buildings are generally cross-cutting with other engineering guidelines in the early phases of the design process. These guidelines aim at enhancing stability, strength, and serviceability of the building [4]. This can be achieved early by means of wind analysis studies, wind tunnel testing and computer simulation tools.

The International Building Code in Section 202 defines high-rise buildings as buildings that are 75 feet ( 23 meters) or greater in height measured from the lowest level of vehicle of fire department access to the floor of the highest occupied story [7].

Historically, the construction of high-rise buildings started at the end of the $19^{\text {th }}$ Century in Chicago, where different inventions like the elevator and the telephone enabled better communications and made this possible [1]. The industrial revolution and the need for warehouses, and also the need for housing stock in Post-war Europe, together with the introduction of new building materials, led to advancements in building design and engineering [8].

The last few decades have witnessed a high-rise building boom that was enabled largely by the advancement of wind analysis and wind engineering. Today, there are high-rise buildings and skyscrapers almost everywhere. Burj Khalifa in Dubai, which reaches a height of 828 meters, is considered the highest building in the world. See Figure 3.
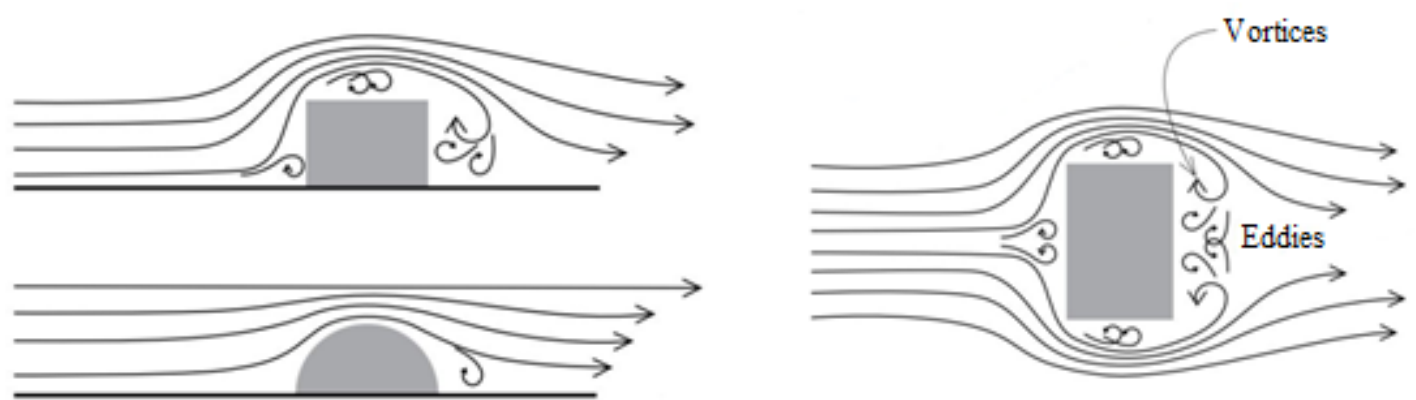

Figure 2. Effect of Shape and Form on Wind Pressure [6] 


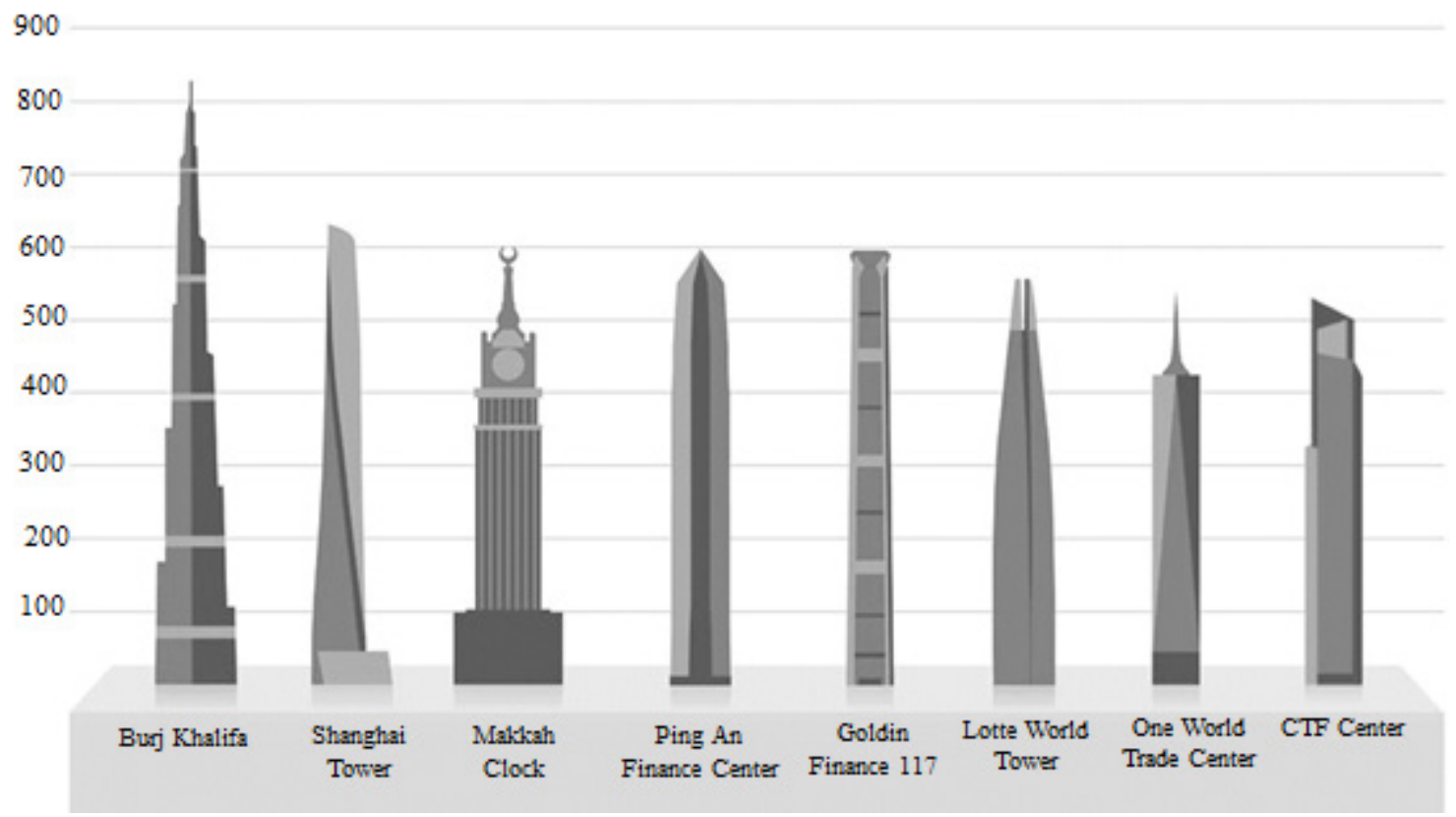

Figure 3. The Highest Buildings in the World in January 2021.

\section{2. (CFD) and Other Early Design Tools}

Computational Fluid Dynamics or (CFD) is a tool that studies fluid flow around and about objects, using computer simulation. The tool solves many industrial and construction need for optimizing parameters in early design and planning [9]. In the early design stages, simulation is important because it depicts how the design process is executed and how the building cost is defined. The biggest amount of cost definition happens in a very early stage of the design process, because in that stage, big decisions are made, and as the building process evolves, smaller decisions are made. The decisions impact on the overall cost of the building is tremendously lower in later stages; Figure 4 shows how building project cost is defined, and how the biggest amount of cost definition happens in the early phases of the design process.

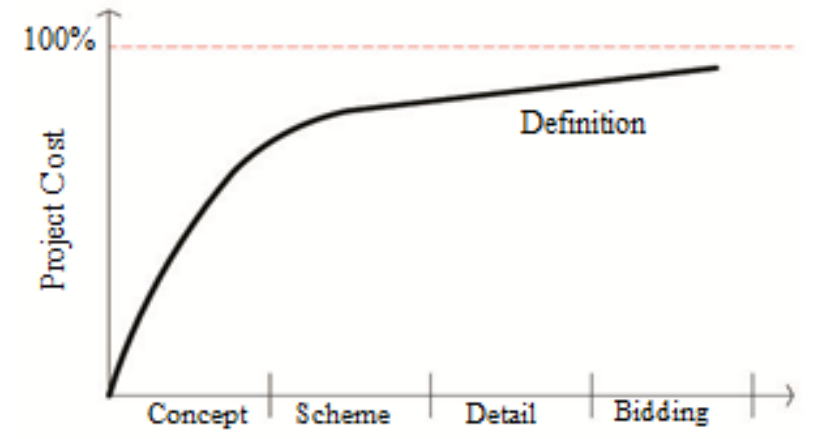

Figure 4. The Biggest Amount of Cost is defined in the Early Phases of the Design Process.

Given these constrains, simulation is a tool that helps in making better design decisions early in the process.
Simulation fundamentally helps make predictions about the physical behavior of buildings and their surroundings which need to be addressed in the design phase to create value for the client and to combat productivity issues [10].

We have lately witnessed many advances in Building Information Modeling (BIM) and also Information Communication Technology (ICT), which have contributed to better productivity and general coordination throughout the construction process [11]. Early design decisions affect construction and Buildability, which is an ability of a building to facilitate ease of construction [12]. Performance-based early design decisions also contribute to better performance against wind and seismic forces, and can effectively cut down on the cost of building materials, which in sequence will render high-rise buildings more sustainable, a shortfall for many cities that are well known for their high-rise building culture [13].

\section{Design Guidelines That Mitigate Wind Loads}

\subsection{Structural Guidelines and Configurations}

To save the internal and exterior layout of a structure, different structural configurations are considered for high-rise buildings. Ching et al. [6] illustrate these different configurations that mitigate lateral forces effects, and help stabilize high-rise buildings, and enhance their serviceability, as can be seen in Figure 5. These structural configurations include: (1) Braced-Frame Structures; (2) Tube Structures; (3) Tube-in-Tube Structures; (4) Diagrid Structures; (5) Trussed or Braced-Tube Structures; (6) 
Bundled-Tube Structures; (7) Space-Truss Structures and (8) Mega-frame Structures, utilizing the entire building perimeter and core to resist both lateral and gravity loads.

Structural stability is crucial in buildings, and especially for high-rise buildings where wind loads increase as we go higher. Performance-based procedures play a vital role in the structural response of high-rise buildings to seismic forces; hence columns are designed to maintain a certain level of damage under the influence of the load applied to resist collapse. According to Rochman et al, the level of damage in the column is usually related to moment capacity, drift capacity ratio, and drift ratio during yielding conditions [14]. A Braced-Frame Structure (1) supports the exterior columns of a rigid frame by using them as web members in the vertical truss system along the exterior. A Framed-Tube Structure (2) meanwhile, is about making benefit of the whole building perimeter to resist wind loads, in which columns are closely spaced and are connected with deep spandrel beams. To enhance the performance of a Framed-Tube structure, belt trusses are often used to equalize the load distribution and to minimize the effects of shear lag often experienced in such structures [15]. A Tube-in-Tube Structure (3) is when a core is added usually of shear walls for better performance against gravity and lateral loads. Diagrid Structures (4) show higher strength and lower ductility compared to tubular structures. When diagonals are added to the framed tube structure it is called Trussed or Braced-Tube structure (5). Bundled-Tube Structures (6) are clusters of individual tubes bundled together at the base to act as a single unit, which serves in breaking the flow of the wind. The Space-Truss Structures (7) use diagonals on the exterior as prisms that extend to the interior frame which helps in stabilizing the structure against vertical and lateral loads.

Mega-Frame Structures (8) usually rise above 60 stories. They utilize mega columns at building corners. These columns are linked by multi story trusses at every 15-20 story intervals, and these are often at mechanical floor levels.

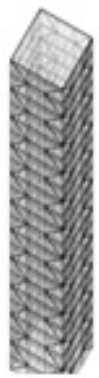

1

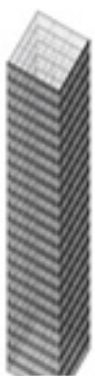

2

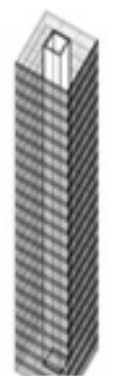

3

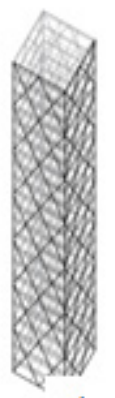

4

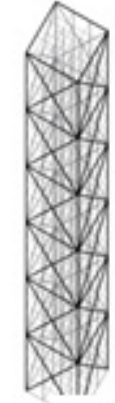

5
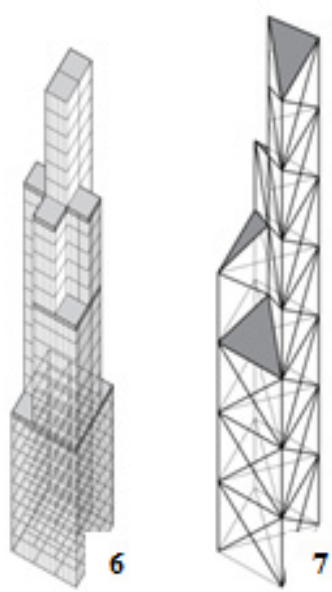

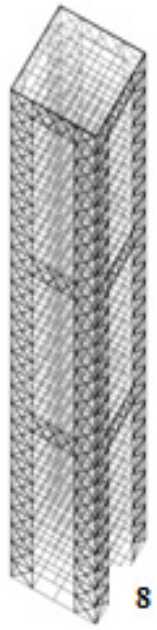

Figure 5. Structural Configurations that Can Mitigate Lateral Forces and Help Stabilize High-Rise Buildings [6]. 


\subsection{Architectural Guidelines and Configurations}

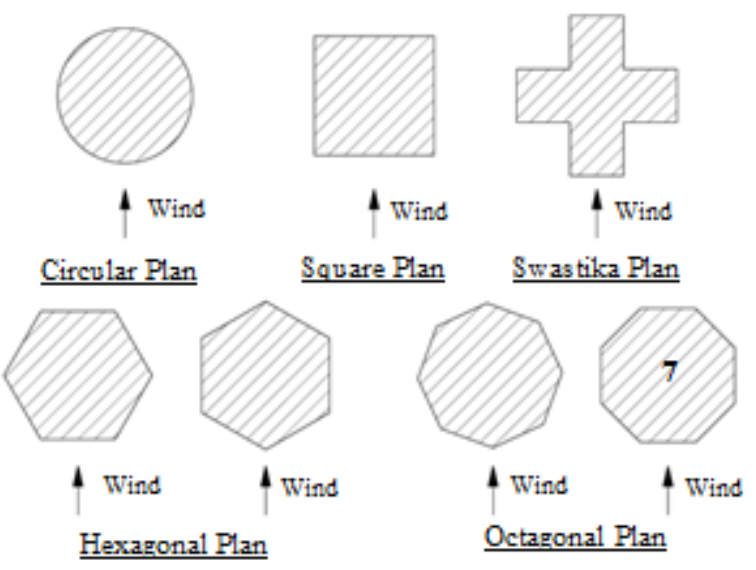

Figure 6. A High-Rise Building with Altered Geometrical Plan Shapes [16].

Many previous studies on lateral loads such as wind loads and earthquake studies have played a significant role in shaping general guidelines for early design decisions.
According to these studies, certain architectural configurations can be used as general framework for an aerodynamic design success.

A study done by Sevalia et al. [16], explained the effects of wind on high-rise buildings with respect to Wind Pressure Coefficient (WPC), wake region, drag force, lift force, etc. Researchers used Computational Fluid Dynamics (CFD) to perform the analysis on different configurations of a plan shape. The plan area of each model configuration was constant at 565 square meters and the height of each model configuration is confined to 300 meters, which can be seen in Figure 6.

The study showed different results for Wind Pressure Coefficient (WPC) and for the Total Drag Force acting on each model, depending on its plan shape configuration. The conclusions of the study are put forward in the following graphs concerning the plan shape relation to the Wind Pressure Coefficient, and also to the Total Drag Force, as is shown in Figure 7 and Figure 8.

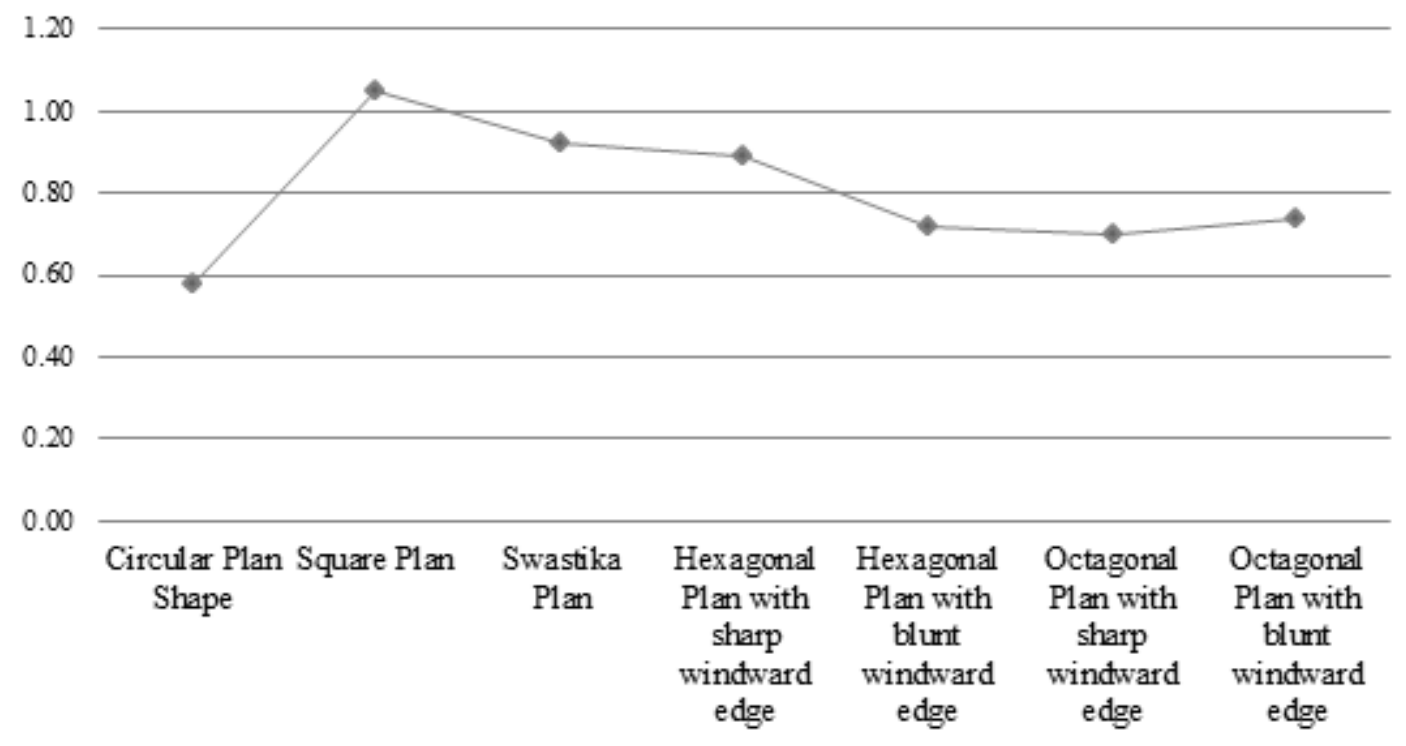

$\multimap$ Wind Pressure Coeffcient

Figure 7. Plan Shape Effect on Wind Pressure Coeffecient [16]. 


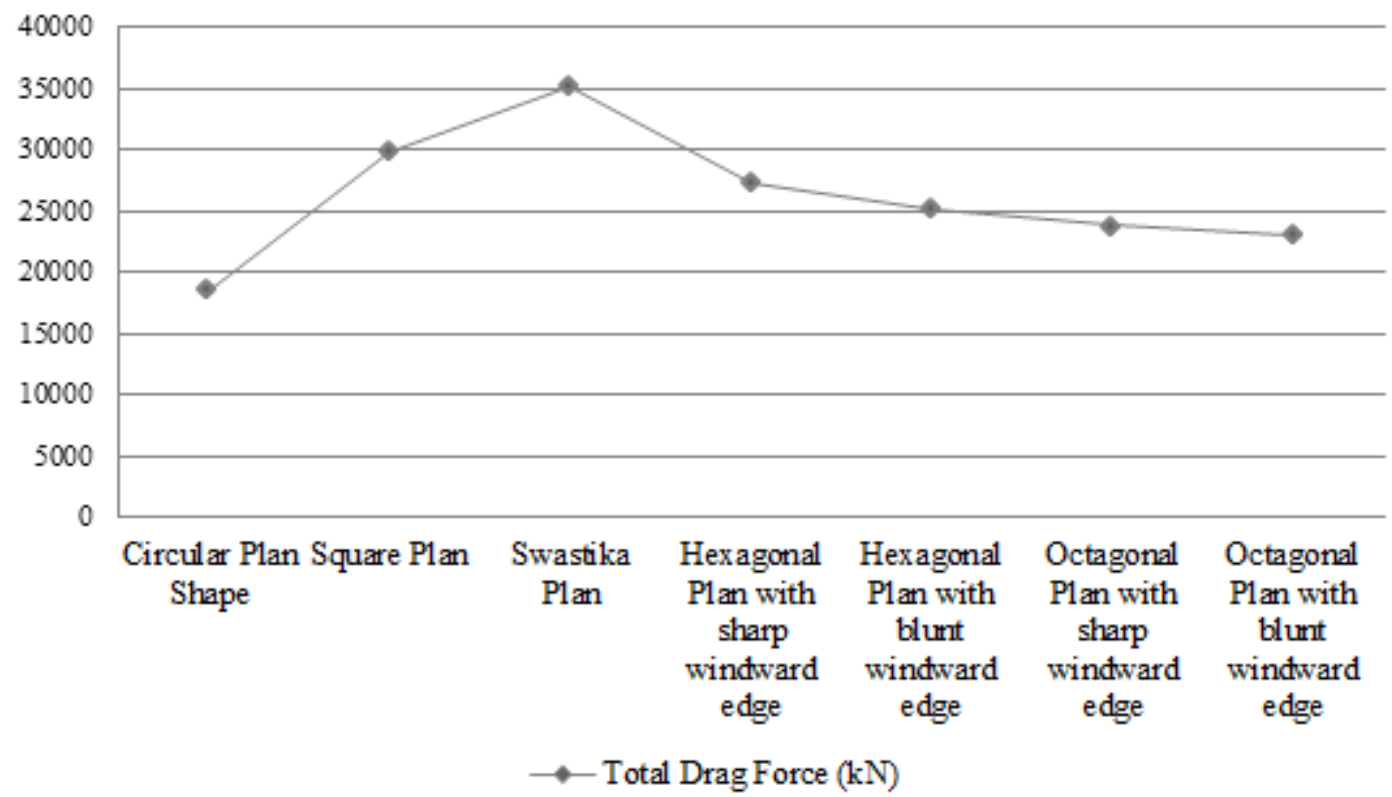

Figure 8. Plan Shape Effect on Total Drag Force [16].

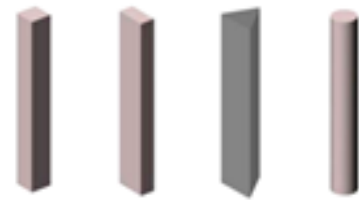

Basic Models (Basic 3D Shapes)
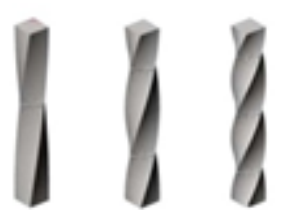

\section{Helical Models (Twisting)}
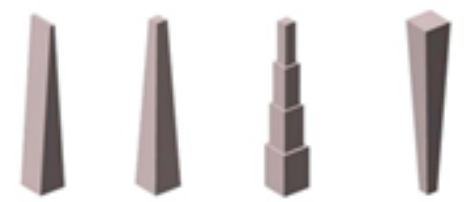

Tapered Models

(Including Setbacks and Bulging Models)
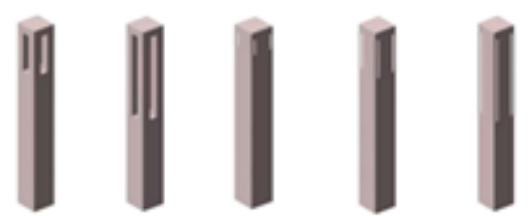

Opening Models

(Porosity)
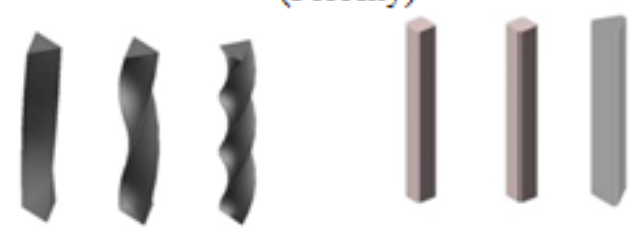
Comer Modified ( Softened)
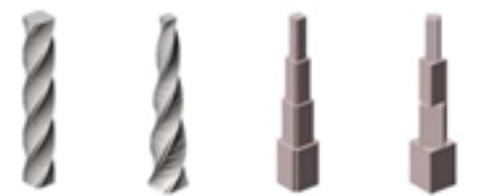

Composite Models (Includding Two or More Configurations)

Figure 9. Different Model Configurations for a High-Rise Building [17].

Another study was done by Tanaka et al. [17], in which aerodynamic force measurements, wind pressure measurements and LES (Large-Eddy Simulation) were conducted for models with various configurations, but with fixed height and volume, as illustrated in Figure 9.

The study concluded that different building configurations resulted in varied aerodynamic performance in mitigating overturning and drag force effects, or in maximizing safety and habitability. Best performing models in each category are summarized in Table 1. According to the study, performance of composite models was mostly superior in all situations. 
Table 1. Best Performing Model Configurations in the Different Categories [17].

\begin{tabular}{cccccc}
\hline $\begin{array}{c}\text { Maximum Mean } \\
\text { Overturning } \\
\text { Moment Coefficient }\end{array}$ & $\begin{array}{c}\text { Maximum Mean } \\
\text { Overturning } \\
\text { Moment Coefficient } \\
\begin{array}{c}\text { Along-wind } \\
\text { Direction) }\end{array}\end{array}$ & $\begin{array}{c}\text { Maximum } \\
\text { Fluctuating } \\
\text { Overturning } \\
\text { Moment Coefficient } \\
\text { (Along-wind } \\
\text { Direction) }\end{array}$ & $\begin{array}{c}\text { Maximum } \\
\text { Fluctuating } \\
\text { Overturning } \\
\text { Moment Coefficient } \\
\text { (Across-wind } \\
\text { Direction) }\end{array}$ & $\begin{array}{c}\text { Safety } \\
\text { Design }\end{array}$ & $\begin{array}{c}\text { Vortex } \\
\text { Shedding }\end{array}$ \\
\hline Tapered Models & Corner Modified & Corner Modified & Corner Modified & Corner Modified \\
Models & Models & Models & Setback \\
Setback Models & Helical Models & Tapered Models & Tapered Models & Helical Models & Square \\
& Helical \\
& Cross Opening & Setback Models & Setback Models & Composite & Models \\
\end{tabular}

In conclusion, according to the majority of previous research on wind effects on high-rise buildings, advice on general aerodynamic design guidelines for shape and model configurations that mitigate wind load effects, these architectural configurations can be summarized in six broad categories include corner softening, tapering, setbacks and hierarchical massing, twisting, porosity and dampers, and mostly, a combination of different configurations.

\subsubsection{Corner Softening}

This entails smoothing sharp edges of a structure in making it aerodynamic. Corner configuration may also include small cut-outs made on the corners to create smoothness and softness and hence lessen bluff bodies. There are different configurations that can be applied to a square plan building; some are described in a study by Elshaer et al. [18], see Figure 10.

According to Holmes [19], Chamfered models reduce the across wind responses by $30 \%$ when compared to the model without modification. Corner-cuts performance is largely dependent on velocity [20], and also on location, where different terrains and different urban settings and neighboring buildings can have effects on turbulence of vortices [21]. One of the most demonstrative examples of using this configuration is the Taipei 101 tower in Taiwan, completed in 2004 .

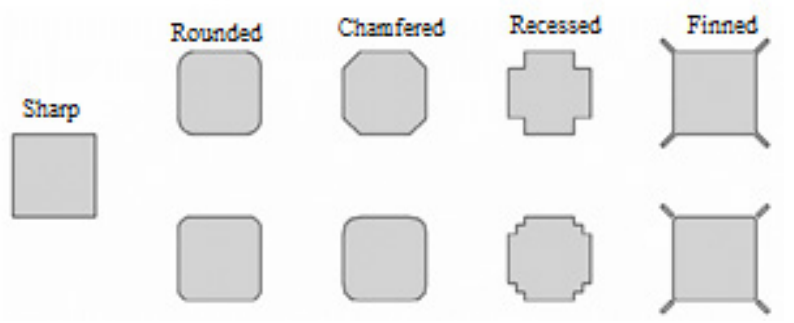

Figure 10. The Different Corner Modifications Applied to a Square Plan [18].

\subsubsection{Tapering}

Tapering entails changing the cross section of a high rise building as we go higher usually smaller. This has a great effect on the reduction of forces in the across-wind direction [22], and also it is minimizing vortex shedding. Many high-rise buildings use this technique of configuration for taming the wind, mainly The Shard in London, completed in 2012, designed by Renzo Piano. See Figure 11.

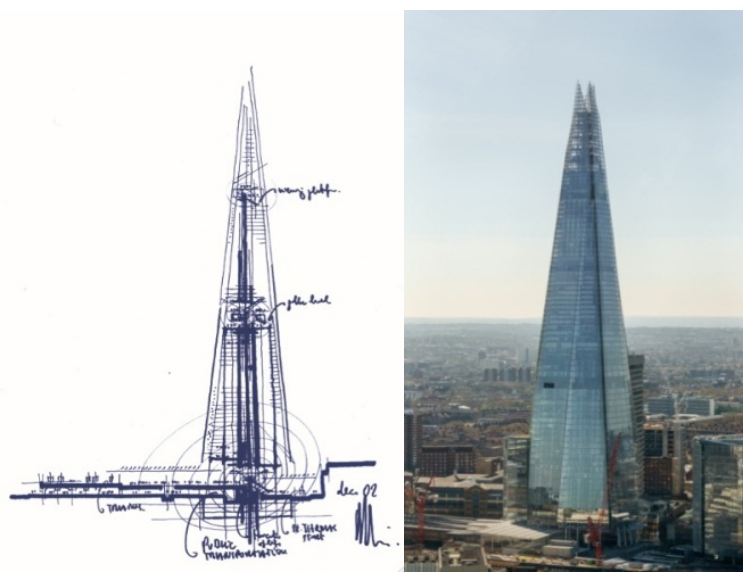

Figure 11. The Shard in London is an Example for Tapering in High-rise Buildings

\subsubsection{Setbacks and Hierarchical Massing}

Setbacks were introduced in New York in 1916 [23], in order to allow for ventilation and sunlight in new zoning rules. Burj Khalifah in Dubai, completed in 2010, follows these rules of setbacks as we go higher. It was designed, with a Y-shaped plan with different configurations that allowed it to reach its height of 828 meters. In a study done on SimScale (CFD simulation platform), as is shown in Figure 12, the tower design with different model configurations illustrates an effective performance in the mitigation of wind effects. 


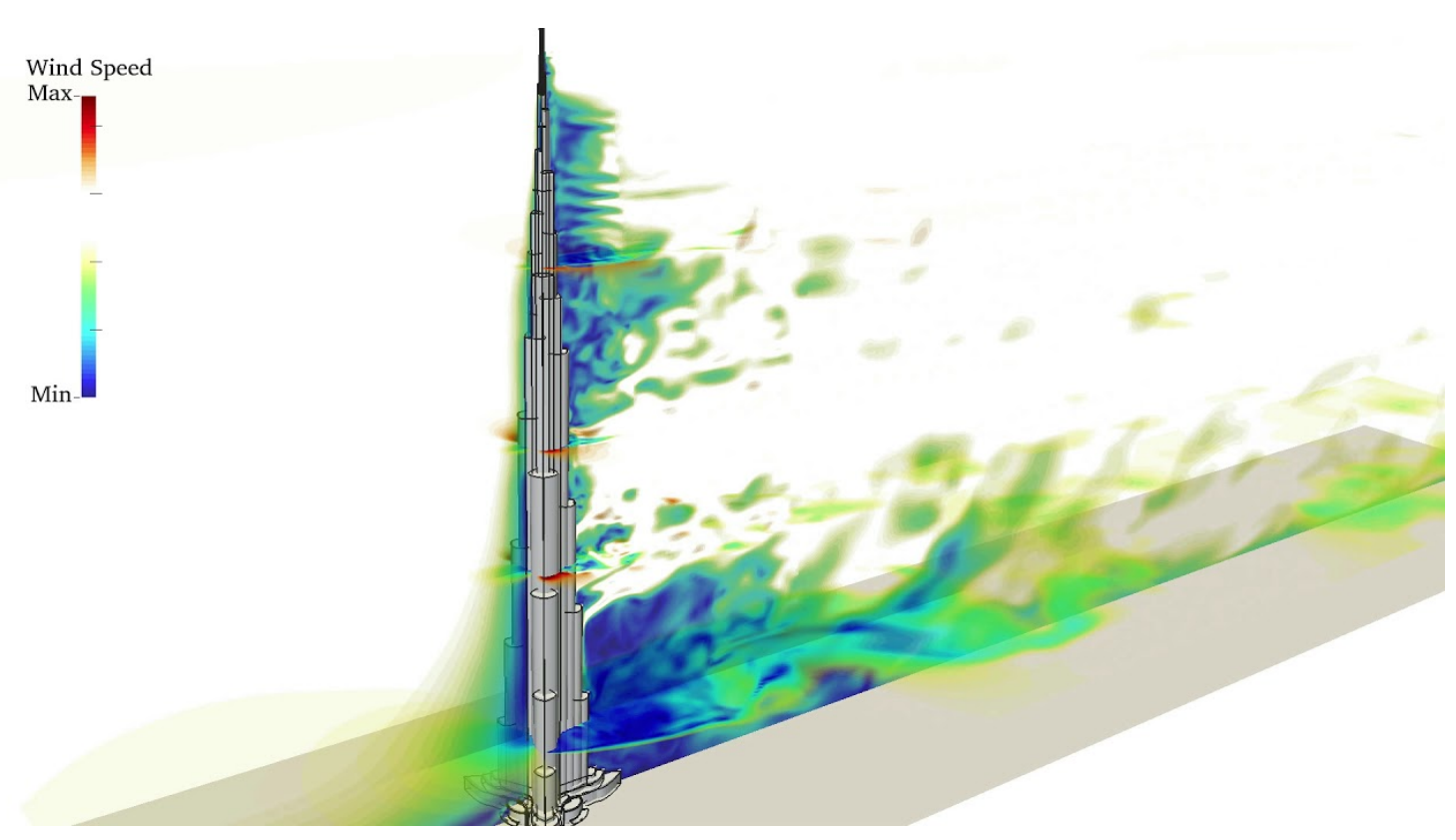

Figure 12. CFD Simulation Using SimScale for Burj Khalifah Showing Effective Building Configurations in Mitigating Wind Effects

\subsubsection{Twisting (Helical Models)}

The best example of a twisting high-rise building is China's Shanghai Tower (Figure 13), the world's second highest building. According to Gensler, the company that is responsible for the design of the tower, wind tunnel testing was performed and repeated several times throughout the conceptual phase of the design process. Twisting in this category refers to a model configuration that aims at scrambling the wind and decreasing bluff bodies along its height.

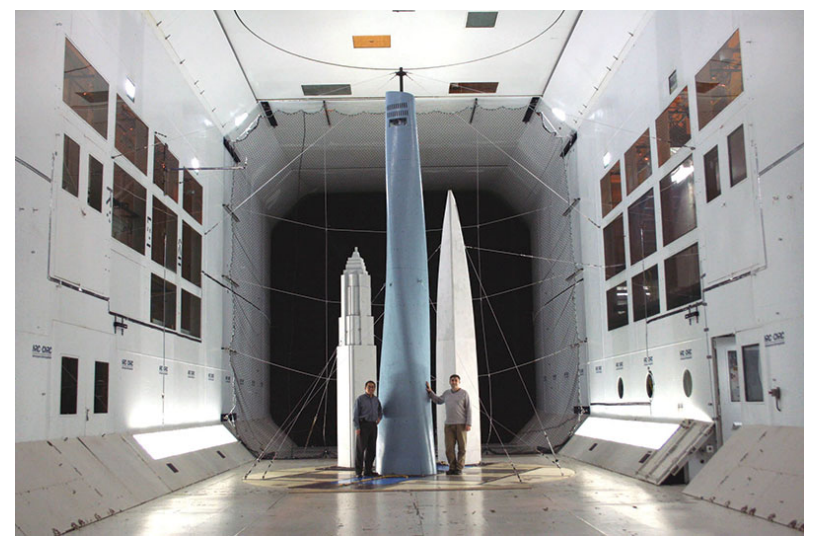

Figure 13. Shanghai Tower Wind Tunnel Testing

\subsubsection{Porosity (Opening Models)}

This model configuration literally means cutting holes in the building model, to allow for undisturbed air flow. This technique apparently has a great effect when the holes or openings are positioned near the top end of the model [24], like The Kingdom Center tower in Saudi Arabia, completed in 2002. Another example is the New York 432 Park Avenue tower, which features intervals of cut-out floors along its height.

\subsubsection{Dampers}

Tuned Mass-Dampers (TMDs) are used to tune down oscillations in buildings and to provide comfort for users [25]. Several buildings use dampers including Taipei 101 in Taiwan, and the 432 Park Avenue in New York. The Dampers are suspended in the upper floors of buildings; they absorb forces by oscillating themselves and thus provide comfort for users and help stabilize high-rise buildings [26].

\section{Two Cases from Amman - Jordan}

The Jordanian Building Code is designed for buildings which do not exceed 100 meters height. Hence, when designing high-rise buildings that exceed 100 meters, architects and engineers adhere to the American or British international codes, which are both used in Jordan. Usually for buildings that exceed 100 meters and are not covered by Jordanian Building Code, wind tunnel analysis can be used simultaneously [27].

The history of high-rise buildings in Amman is fairly recent. The Amman Development Plan of 2007 included an intensification growth rather than sprawl strategy, by means of addressing new market and investor demands for high-rise towers [28]. Towers, according to the plan initiated by the Greater Amman Municipality (GAM), add to economic and investment value of the city. Selected areas of development in the city were chosen based on different criteria, one of which is topography. These development areas that include high-rise buildings are within High Density Mixed Use areas (HDMU), as is shown in Figure 14. 


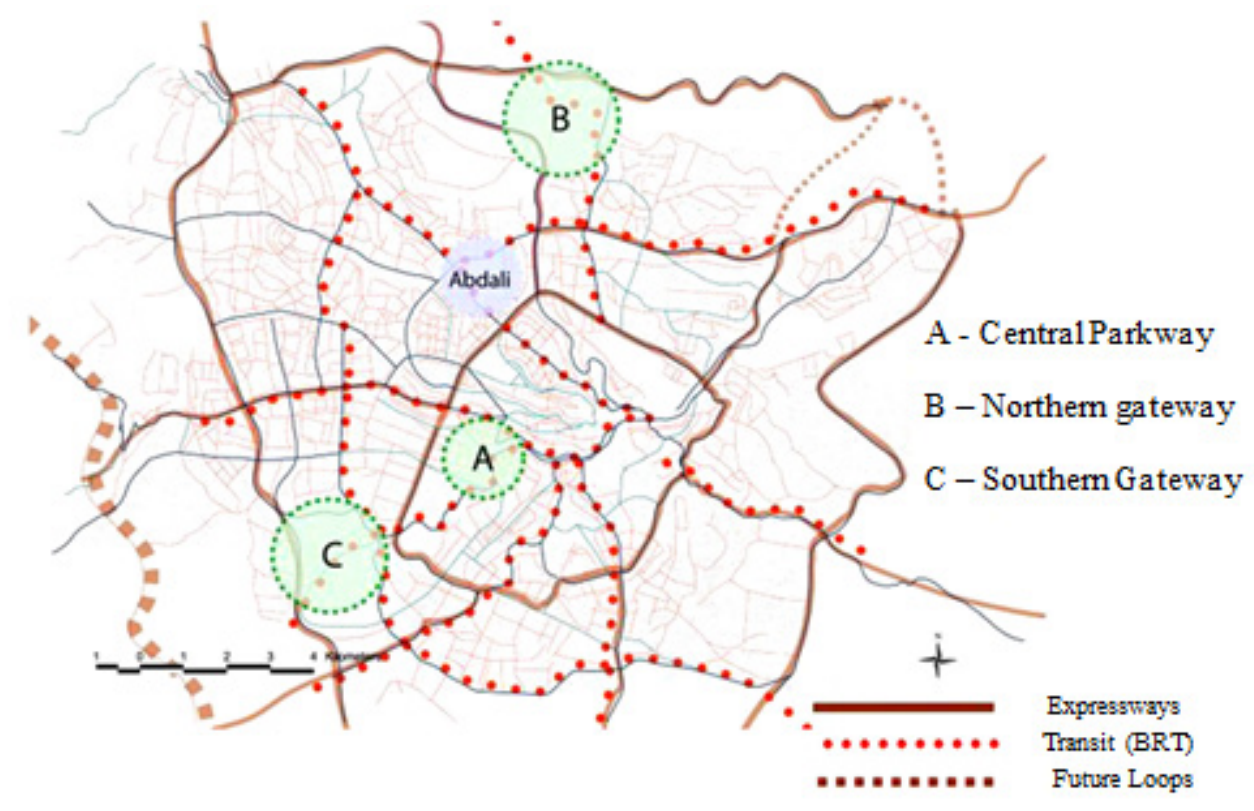

Figure 14. Areas for High-Rise Buildings Development within (HDMU) Zones for the City of Amman [28]

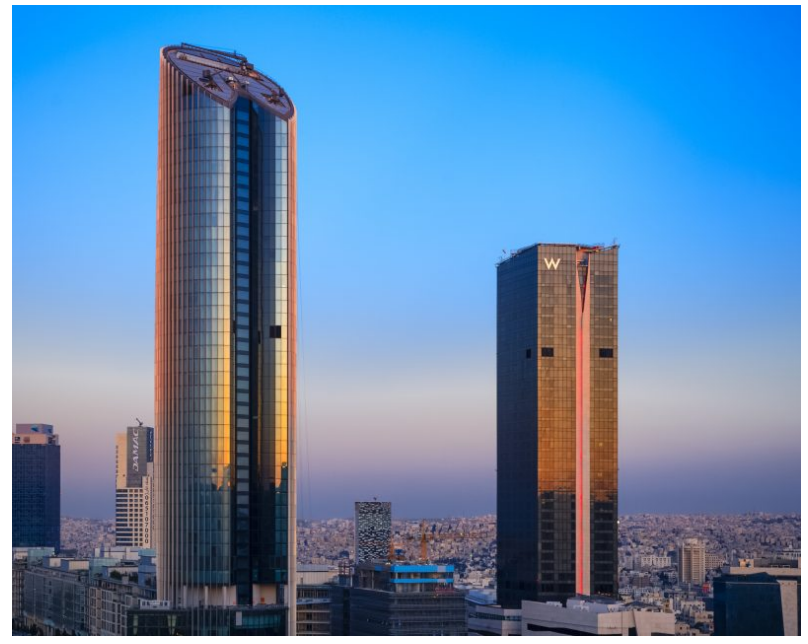

Figure 15. The Two Highest Buildings in Amman as Seen in the Skyline of the City

Al-Abdali development, which is one of the main high-rise building areas in the Amman Plan, hosts two of the highest buildings in Amman: The Rotana Hotel Tower and The W Hotel Tower. Both can be seen in the skyline of Amman in Figure 15. The two developments convey the most advanced wind engineering technologies used in the country and both feature aerodynamic design measures.

\subsection{Rotana Tower Hotel}

The Rotana Tower Amman which was built between 2005 and 2016 is the highest built tower in the new development of Al-Abdali district. It was designed by the Paris located firm Architecture-Studio, for the Emirates Tourism Investment Company. This tower is the highest building in Amman, and its design features a core design with an external grid, which leaves the internal spaces free.

The building, which is 188 meters, has a significant slenderness and variable geometry which includes bulging in the model shape and varying plan shape to scramble the wind. Wind tunnel testing was performed for the Rotana Amman Hotel, as buildings that exceed 100 meters do not conform to the Jordanian Building Code. The building grows into an ellipse shape as we go higher until it reaches the 23rd floor, it becomes a circle and then it tapers into an ellipse again. This aerodynamic configuration causes bulging along the z-axis, which serves against wind loads, as is shown in Figure 16. 

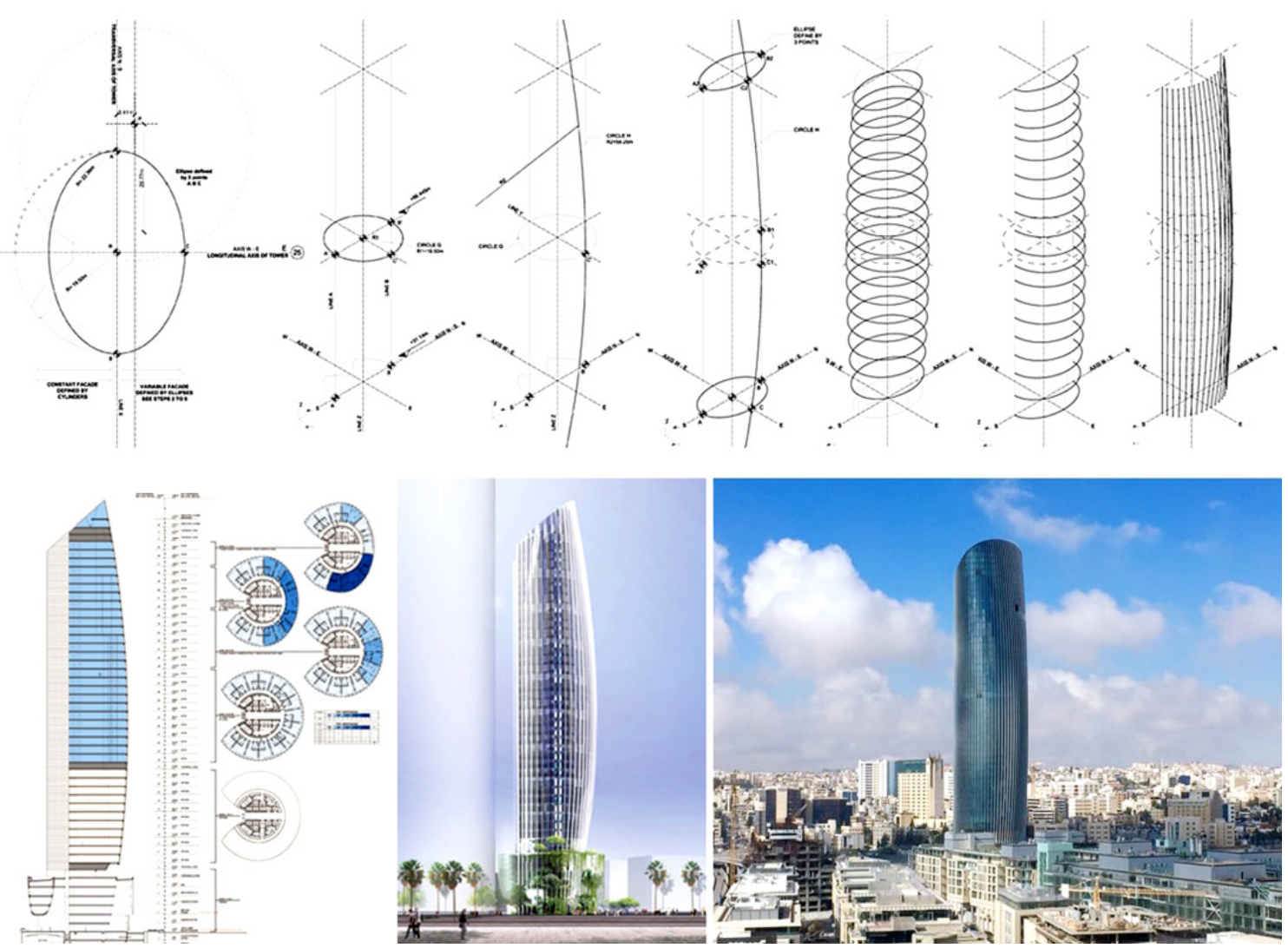

Figure 16. Core Based Design and Bulging Along the Y Axis Serves Against Wind Loads for Rotana Tower.

The building is a central core design, where shear walls are used along the core. Raft foundation was used, with piles under raft to reach the Flint stone layer at 25 meters below raft foundation level. Piles were cast in situ with measurements reaching about 1.5 meters in diameter, as is shown in Figure 17.

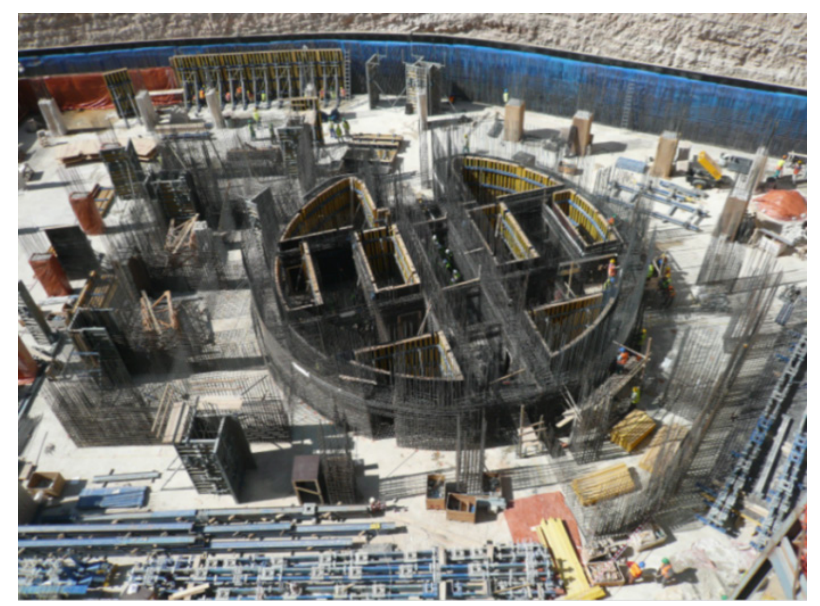

Figure 17. Foundations for the Rotana Tower shows Raft Foundation and the Core Base Design.

For the Rotana Tower design, early design decisions included choice of plan and model configuration, choice of structural system, foundation type, and façade solutions. See Figure 18.

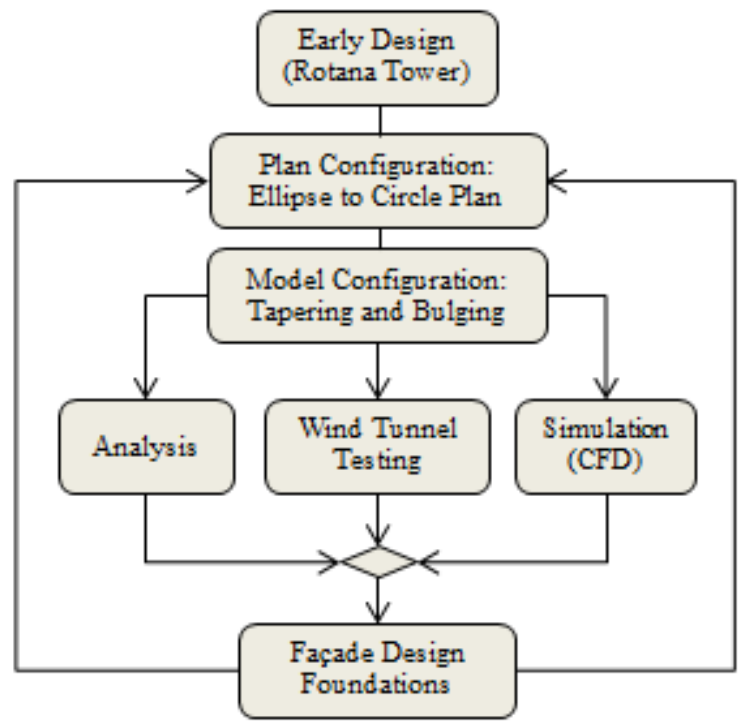

Figure 18. Design Process for Aerodynamic Design of Rotana Tower Amman

\subsection{Saraya Tower / W Hotel Amman}

The other high-rise building case from Amman, capital of Jordan that is the second highest building in the city is The Saraya Holdings Headquarters. The building is currently occupied by the newly established W Hotel. Located in Al-Abdali development area, and completed in 
2016. The building was designed by Perkins and will reach a height of 142 meters. According to WindTech, the company that carried out the wind analysis study for the development, the tower rises from a podium, which in concept, features a canyon cutting through its elevation. This configuration of form, in addition to its location within the Al-Abdali built precinct, meant that wind tunnel testing is required. Wind tunnel testing was performed on design models in the early design phases, for both the building without the surrounding buildings, and also with the proposed future development precinct, as is shown in Figure 19.

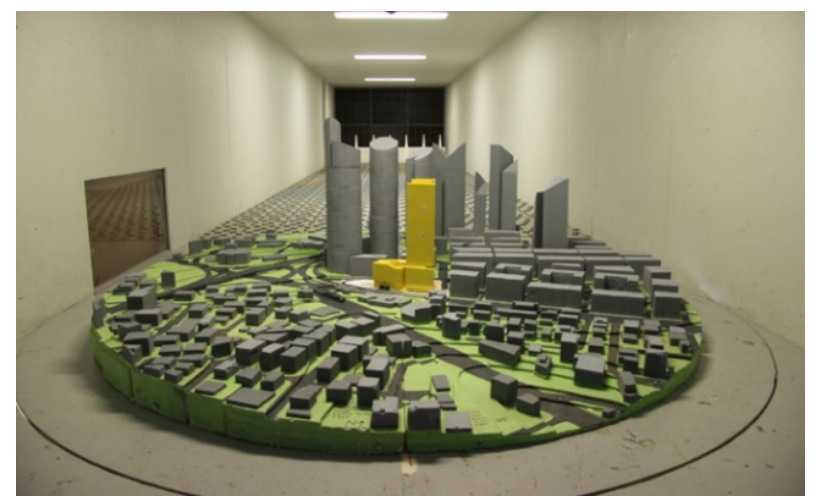

Figure 19. Wind Tunnel Testing for $\mathrm{W}$ Hotel Performed with the Proposed Future Development Precinct.

The result of wind tunnel testing suggested that the worst case peak base moments in the future would be along the $\mathrm{X}$-axis; contrary to code estimates, the $\mathrm{Y}$-axis resulted in considerably lower loads. Because of this result, the over-design of the $\mathrm{Y}$-axis peak base moments were modified and reduced accordingly.

Also, a study was performed on the cladding pressure of the façade in the early design phase, and this enabled the re-design of the critical areas of the façade between the tower and podium, and for the canyon rift in the podium mass to be accounted for. See Figure 20.

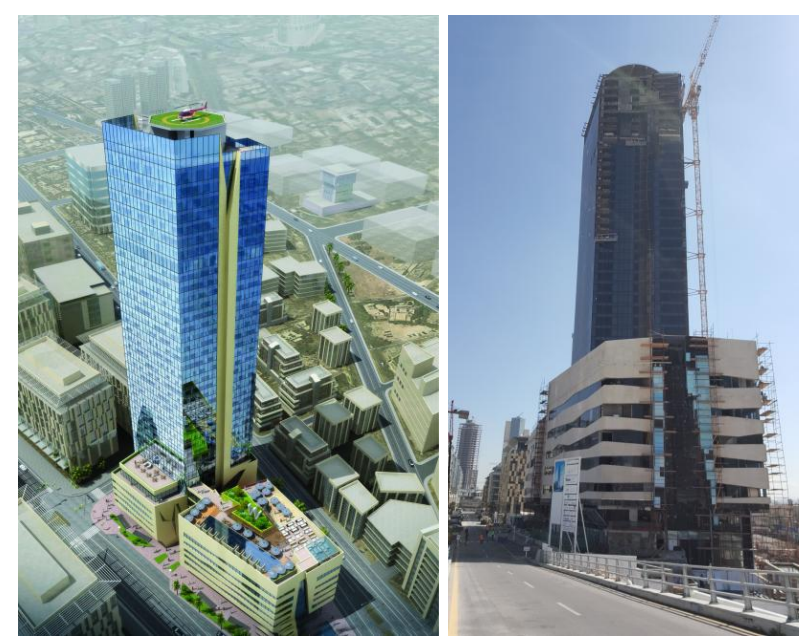

Figure 20. W Hotel in Amman Visualization Model and During Construction Showing the Podium and Tower of the Development.
A pedestrian wind study was also performed using wind tunnel testing in the early design phase, and this was an important issue to be considered especially in Al-Abdali area, which is composed of a number of high-rise developments, where a large pedestrian area is tunneled between the high towers.

Using wind analysis and CFD and also wind tunnel testing is important in the early phase of the design as it affects decision making.

For the $\mathrm{W}$ Tower design, early design decisions included choice of plan and model configuration, choice of structural system, foundation type, and façade solutions. In the design development phase façade modifications were performed and also a pedestrian wind comfort analysis study. See Figure 21.

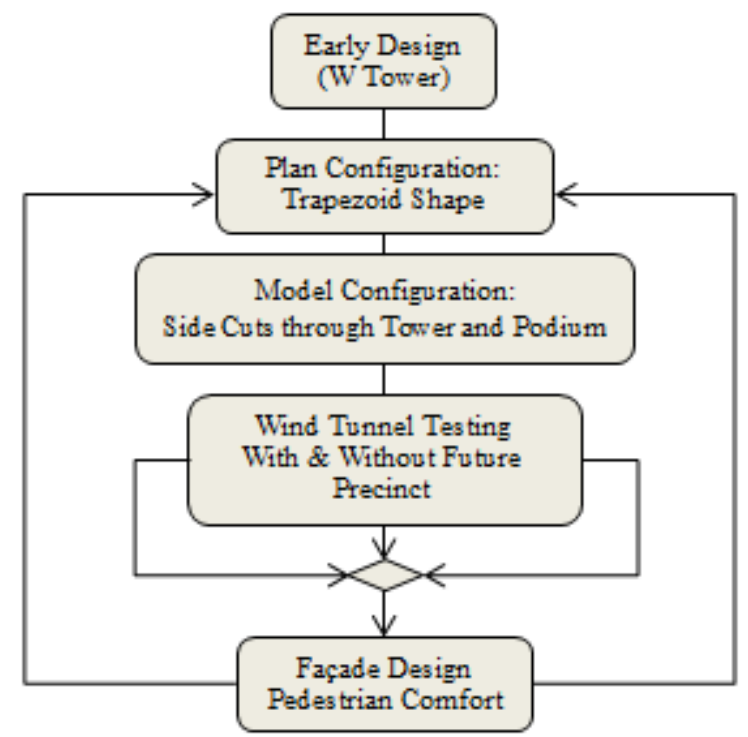

Figure 21. Design Process for Aerodynamic Design of W TowerAmman.

\section{Conclusions}

The research concludes that wind loads mitigation in high-rise buildings is affected by early-stage design decisions, especially those that concern the model and plan configurations. By incorporating tools such as wind analysis studies, wind tunnel testing, and (CFD) simulations into the design process, as is shown in Figure 22 , interdisciplinary aerodynamic design decisions can be made. Collaboration is significant in decision making in the early design phase, as it widens the perspective and develops better design strategies and configurations.

To conclude, Amman is a city which is still new to high-rise buildings; hence, further research in the fields of wind engineering and aerodynamic design can contribute to better understanding of aerodynamic structures, and advance architectural design and research in Jordan. Collaboration between different stakeholders, like investors, legislators, architects and engineers, etc. can also 
contribute to the success of designing more stable and convenient high-rise buildings in the city using general guidelines that are found in this study, or elsewhere in literature.

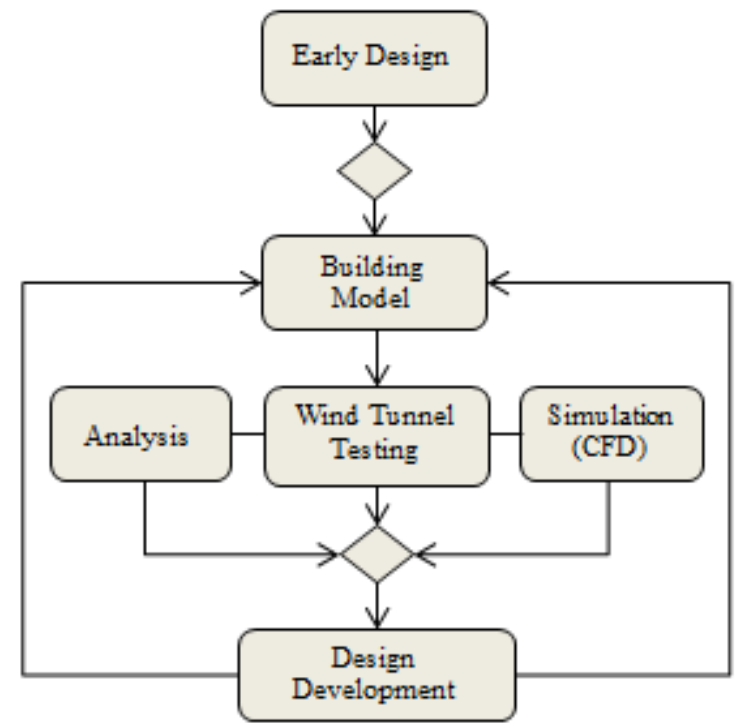

Figure 22. Design Process for Aerodynamic Design of a High-rise Building

\section{REFERENCES}

[1] M. Ali, K. Al-Kodmany. Tall Buildings and Urban Habitat of the 21st Century: A Global Perspective, Buildings, Vol. 2, No. 4, pp. 384-423, 2012. https://doi.org/10.339 0/buildings2040384.

[2] E. Simiu, D. Yeo. Wind Effects on Structures: Modern Structural Design for Wind, Wiley-Blackwell, New York, 2019.

[3] A. G. Davenport. The Response of Slender Line-like Structures to a Gusty Wind, Proceedings of the Institution of Civil Engineers, Vol. 23, No. 3, pp. 389-408, 2015. https://doi.org/10.1680/iicep.1962.10876.

[4] P. Mendis, T. Ngo, N. Haritos, A. Hira, B. Samali, J. Cheung. Wind Loading on Tall Buildings, Electronic Journal of Structural Engineering, Vo. 7, No. 1, pp. 41-54, 2007.

[5] Z. Forrest, S. Michael, T. Alex, A. Andrew. Across-wind Load on Rectangular Tall Buildings, Structural Engineer, Vol. 95, No. 3, pp. 36- 41, 2017.

[6] F. Ching, B. Onouye, B. Zuberbuhler. Building Structures Illustrated. Wiley-Blackwell, New York, 2013.

[7] International Code Council (ICC). International Building Code, International Code Council, Falls Church, 2018.

[8] J. Eisele, E. Kloft. High-Rise Manual, Birkhäuser Architecture, Basel, 2003.

[9] S. Murakami. CFD and Building Environment Design, China Architecture \& Building Press, Beijing, 2007.

[10] M. El. Reifi, S. Emmitt. Perceptions of Lean Design
Management, Architectural Engineering and Design Management, Vol. 9, No. 3, pp. 195-208, 2013. https://doi.org/10.1080/17452007.2013.802979.

[11] S. Kaijima, R. Bouffanais, K. Willcox, S, Naidu. Computational Fluid Dynamics for Architectural Design, Proceedings of the 18th International Conference on Computer-Aided Architectural Design Research in Asia (CAADRIA 2013), Hong Kong, and Center for Advanced Studies in Architecture (CASA), Department of Architecture-NUS, Singapore, pp. 169-178, 2013. DOI: 10.1002/ad.1566.

[12] Construction Industry Research and Information Association (CIRIA). Buildability: An Assessment, CIRIA, London, 1983.

[13] X. Jin, G. Zhang, J. Zuo, S. Lindsay. Sustainable High-rise Design Trends - Dubai's Strategy, Civil Engineering and Architecture, Vol. 1, No. 2, pp. 33-41, 2013. DOI: 10.13189/cea.2013.010201.

[14] T. Rochman, N. Rasidi, Sumardi, E. Cahya, A. Priyant. The Effect of Columns Configuration on High-rise Building Using Performance-based Design, Civil Engineering and Architecture, Vol. 8, No. 6, pp. 1144-1166, 2020. DOI: 10.13189/cea.2020.080601

[15] W. Alhaddad, Y. Halabi, H. Xu, H. Lei. Outrigger and Belt-Truss System Design for High-Rise Buildings: A Comprehensive Review Part II-Guideline for Optimum Topology and Size Design, Advances in Civil Engineering, Vol. 2020, pp. 1-30, 2020. DOI: 10.1155/2020/2589735.

[16] [16] J. Sevalia, A. Desai, S. Vasanwal. Effect of Geometric Plan Configuration of Tall Building on Wind Force Coefficient Using CFD, International Journal of Advanced Engineering Research and Studies, Vol. 1, No. 2, pp. $127-130,2012$.

[17] H. Tanaka, Y. Tamura, K. Ohtake, M. Nakai, Y. C. Kim, E. K. Bandi. Aerodynamic and Flow Characteristics of Tall Buildings with Various Unconventional Configurations, International Journal of High-Rise Buildings, Vol. 2, No. 3, pp. 213-228, 2013.

[18] A. Elshaer, G. Bitsuamlak, A. El Damatty. Enhancing Wind Performance of Tall Buildings Using Corner Aerodynamic Optimization, Engineering Structures, Vol. 136, No. 1, pp. 133-148, 2017.https://doi.org/10.1016/j.engstruct.2017.01. 019.

[19] J. Holmes. Wind Loading of Structures, CRC Press, Boca Raton, 2015.

[20] H. Kawai. Effect of Corner Modifications on Aeroelastic Instabilities of Tall Buildings, Journal of Wind Engineering and Industrial Aerodynamics, Vol. 74, No. 76, pp. 719-728, 1998. https://doi.org/10.1016/S0167-6105(98)00065-8.

[21] K. Kwok, N. Isyumov. Aerodynamic Measures to Reduce the Wind-induced Response of Buildings and Structures, Proceedings of Structural Engineers World Congress, San Francisco, California, pp. 86-100, 1998. DOI: 10.1016/j.engstruct.2018.08.031.

[22] K. Young-Moon, K. P. You. Dynamic Responses of a Tapered Tall Building to Wind Loads, Journal of Wind Engineering and Industrial Aerodynamics, Vol. 90, No. 12-15, pp. 1771-1782, 2002. https://doi.org/10.1016/S0167 
$-6105(02) 00286-6$.

[23] W. A. Weiss. Skyscraper Zoning: New York's Pioneering Role, Journal of the American Planning Association, Vol. 58 ,

No. 2, pp. 201-212, 2009. https://doi.org/10.1080/0194436 9208975794.

[24] R. Dutton, N. Isyumov. Reduction of Tall Building Motion by Aerodynamic Treatments, Journal of Wind Engineering and Industrial Aerodynamics, Vol. 36, No. 17, pp. 739-747, 1990. https://doi.org/10.1016/0167-6105(90)90071-J.

[25] A. Kareem, T. Kijewski, Y. Tamura. Mitigation of Motions of Tall Buildings with Specific Examples of Recent Applications, Wind and Structures an International Journal,
Vol. 2, No. 3, pp. 201-251, 1999. DOI: 10.12989/was.1999 .2.3.201.

[26] R. Bashor, A. Kareem. Probabilistic Performance Evaluation of Buildings: An Occupant Comfort Perspective, Proceedings of the 12th International Conference on Wind Engineering (ICWE12), Cairns, Australia, pp. 1335-1342, 2007.

[27] Jordanian Building Code (JBC). Code of Loads, Ministry of Public Works and Housing (MPWH), Amman, Jordan, 2006.

[28] Grater Amman Municipality (GAM). High Rise Towers: An Integral Part of Amman's Urban Landscape, GAM, Amman, 2007. 